\title{
PENERAPAN METODE PROFILE MATCHING DALAM MEREKOMENDASIKAN BIBIT KELAPA SAWIT
}

\author{
Ika Septi Mahdia ${ }^{1}$, Solikhun², M. Fauzan ${ }^{3}$ \\ ${ }^{1}$ Mahasiswa Program Studi Sistem Informasi, STIKOM Tunas Bangsa Pematangsiantar \\ ${ }^{2,3}$ Dosen STIKOM Tunas Bangsa Pematangsiantar \\ Email: ${ }^{1}$ ikaseptimahdia@gmail.com, ${ }^{2}$ solikhun.atb@gmail.com, ${ }^{3}$ mfauzan57@yahoo.com
}

\begin{abstract}
Abstrak
Tanaman kelapa sawit merupakan tanaman perkebunan yang dibudidayakan dan membutuhkan perawatan yang intensif, bibit kelapa sawit merupakan factor utama dalam keberhasilan budidaya perkebunanan kelapa sawit. Tanaman bibit kelapa sawit yang berkualitas akan memberikan hasil panen yang memuaskan, bibit kelapa sawit sebaiknya diperoleh dengan pemilihan bibit yang unggul dan pemeliharaan yang baik, dalam pembibitan dilakukan dengan mengikuti tahap yang ada, perkebunan kelapa sawit merupakan usaha jangka panjang dan perawatan bibit kelapa sawit harus di perhatikan dan dikelola dengan insentif untuk menjamin produksi dan hasil usaha yang optimal dikemudian hari. Penelitian ini bertujuan untuk menentukan bibit kelapa sawit yang unggul di PTPN IV Kebun Bah Jambi,. Dalam pembibitan dilakukan dengan mengikuti tahap yang ada, penelitian ini menggunankan Sistem Pendukung Keputusan (SPK) metode Profile Matching. Metode ini dapat digunakan untuk menyelesaikan masalah semi terstruktur dengan menghitung konsistensi menggunakan metode Profile Matching, jika nilai konsisten dihasilkan konsisten dapat dijadikan acuan untuk memberikan peringkat bibit kelapa sawit yang unggul di PTPN IV Kebun Bahjambi. Untuk hasil dari penelitian dapat dihasilkan bahwa lebih mudah dalam merekomendasikan bibit kelapa sawit dan menjadi masukan terhadap perkebunan dalam merekomendasikan bibit kelapa sawit terbaik.
\end{abstract}

Kata Kunci: Bibit kelapa Sawit, Sistem Pendukung Keputusan, Profile Matching

\begin{abstract}
Oil palm plants are plantation crops that are cultivated and require intensive care, oil palm seeds are a major factor in the success of oil palm plantation cultivation. Quality palm oil seedlings will provide satisfactory yields, oil palm seedlings should be obtained with superior seed selection and good maintenance, in nurseries carried out by following the existing stages, oil palm plantations are long-term business and maintenance of oil palm seeds must be be considered and managed with incentives to ensure optimal production and business results in the future. This study aims to determine quality oil palm seeds in PTPN IV Bah Jambi Plantation. In the nursery is carried out by following the existing stage, this research uses Decision Support System (SPK) Profile Matching method. This method can be used to solve semi-structured problems by calculating consistency using the Profile Matching method, if consistent values are generated consistently can be used as a reference for ranking quality oil palm seeds in PTPN IV Bahjambi Plantation. For the results of the research it can be produced that it is easier to recommend oil palm seedlings and be an input to the plantation in recommending the best oil palm seeds.
\end{abstract}

Keywords: Palm oil seeds, Decision Support System, Profile Matching

\section{PENDAHULUAN}

Bibit kelapa sawit merupakan salah satu jenis tanaman perkebunan yang memiliki posisi penting dalam sektor pertanian dan khususnya perkebunan, karena dari sekian banyak tanaman yang menghasilkan minyak atau lemak, kelapa sawit yang menghasilkan nilai ekonomi terbesar per hektarnya didunia (Balai Informasi Pertanian 1990). Mengambil keputusan dalam pemilihan pertumbuhan awal bibit merupakan periode kritis yang sangat menentukan keberhasilan tanaman dalam mencapai pertumbuhan yang baik dipembibitan pertumbuhan dan figur bibit tersebut sangat ditentukan oleh kecambah yang ditanam.

Untuk meningkatkan kualitas bibit kelapa sawit, tentu perlu dukungan dari perusahaan. Segala bentuk dukungan sudah semestinya diperlukan dalam hal merekomendasikan bibit kelapa sawit yang memiliki potensi baik. Maka perlu dipikirkan usaha peningkatan kualitas dan kuantitas produksi kelapa sawit secara tepat agar target yang diinginkan dapat tercapai dengan maksimal.

Sumber data ini didapatkan berdasarkan data bibit kelapa sawit yang dihasilkan oleh PTPN IV Unit Kebun Bah Jambi dan merupakan perusahaan milik pemerintah. PTPN IV memiliki 30 unit usaha yang akan mengelola budidaya kelapa sawit dan satu unit usaha yang mengelola budidaya teh dan satu unit kebun plasma kelapa sawit, serta satu unit usaha perbengkelan (PMT Dolok Ilir) yang menyebar di 9 kabupaten, yaitu Kabupaten Langkat, Deli Serdang, Serdang Bedagai, Simalungun, Asahan, Labuhan Batu, Padang Lawas, Batubara dan Mandailing Natal (PTPN IV Persero). Berdasarkan latar belakang tersebut maka perusahaan perlu mengambil sebuah keputusan dalam pemilihan bibit kelapa sawit terbaik, yang mana pemilihan bibit kelapa sawit terbaik tersebut diharapkan akan meningkatkan efektivitas pengambilan keputusan manager terhadap suatu pemecahan masalah. Permasalahan dalam pemilihan bibit kelapa sawit terbaik tersebut dapat diatasi menggunakan Sistem Pendukung Keputusan (Decision Support System). Dalam hal ini penulis mengambil sebuah metode yaitu Profile Matching. Metode ini penulis pilih karena Metode Profile Matching merupakan suatu proses yang sangat penting dalam manajemen Sumber Daya Manusia (SDM) dimana terlebih dahulu ditentukan sebagai mekanisme dalam pengambilan keputusan dengan mengansumsikan bahwa terdapat tingkatan variable predicator yang ideal yang harus dipenuhi oleh subjek yang di teliti, (Menurut Kusrini 2007). Untuk itu penulis mengambil judul "Penerapan Metode Profile Matching Dalam 
Merekomendasikan Bibit Kelapa Sawit”. Diharapkan penerapan metode ini dapat dijadikan kontribusi untuk perusahaan dalam hal pemilihan bibit kelapa sawit yang ada di tempat perusahaan, dalam mengambil keputusan secara tepat, tepat dalam menentukan bibit kelapa sawit sehingga dapat membantu proses pemilihan bibit kelapa sawit.

\section{TEORITIS}

\subsection{Sistem Pendukung Keputusan}

Sistem pendukung keputusan merupakan sistem informasi interaktif yang menyediakan informasi, pemodelan, dan pemanipulasian data yang dibangun untuk mendukung solusi atas suatu masalah untuk mengevaluasi peluang. Sistem pendukung keputusan digunakan untuk menyelesaikan masalah yang tidak terstruktur dan dirancang untuk mendukung seluruh tahap pengambilan keputusan [1][2].

\subsection{Metode Profile Matching}

Metode Profile Matching adalah sebuah mekanisme pengambilan keputusan dengan mengasumsikan bahwa terdapat variable predicator yang ideal yang harus dimiliki, bukannya tingkat minimal yang harus dipenuhi atau dilewati dalam proses Metode Profile Matching Modelling secara garis besar merupakan proses membandingkan antara nilai data actual dari suatu profile yang akan dinilai dengan nilai profil yang diharapkan, sehingga dapat diketahui perbedaan kompetensinya (disebut juga gap) [3].

1. Core Factor (Faktor Utama)

Core factor (CF) merupakan aspek (kompetensi) yang paling menonjol/paling dibutuhkan oleh suatu jabatan yang diperkirakan dapat menghasilkan kinerja optimal.Untuk menghitung core factor digunakan persamaan:

$\mathrm{NCI}=\frac{\sum \mathrm{NC}}{\sum \mathrm{CI}}$

Keterangan :

$\mathrm{NCI}=$ Nilai rata - rata Core Factor

$\mathrm{NC}=$ Jumlah total nilai Core Factor

IC = Jumlah item Core Factor

2. Secondary Factor (Faktor Pendukung)

Secondary factor (SF) adalah item-item selain aspek yang ada pada core factor. Untuk menghitung secondary factor digunakan persamaan :

$\mathrm{NSI}=\frac{\sum \mathrm{NS}}{\sum \mathrm{IS}}$

Keterangan :

NSI = Nilai rata - rata Secondary Factor

NS = Jumlah total nilai Secondary Factor

IS = Jumlah item Secondary Factor

Rumus diatas adalah rumus untuk menghitung core factor dan secondary factor dari aspek Kualitas. Rumus tersebut juga digunakan untuk menghitung core factor dan secondary factor dari aspek harga dan Pelayanan.

3. Perhitungan Rangking

Hasil Akhir dari proses profile matching adalah rangking dari kandidat yang diajukan untuk mengisi suatu jabatan /posisi tertentu. Penentuan mengacu rangking pada hasil perhitungan yang ditujukan pada persamaan berikut :

Rangking :

$50 \% \mathrm{NAD}+30 \% \mathrm{NAB}+20 \% \mathrm{NAT}$

Keterangan :

NAD $=$ Nilai Akhir Daun

NAB $=$ Nilai Akhir Batang

NAT $=$ Nilai Akhir Tanah

Pada penelitian ini, penentuan kriteria yang akan digunakan ditentukan oleh Pimpinan (Decision Maker) yang disesuaikan dengan aturan-aturan yang ada pada objek penelitian [3]

\subsection{Teknik Pengumpulan Data}

Pada pengumpulan data ini variable penelitian yang dibutuhkan adalah data bibit kelapa sawit dan data ini didapat ketika penulis Melakukan Praktek Kerja Lapangan di PTPN IV Unit Kebun Bah Jambi. Data yang digunakan sebagai objek penelitian didapat dari hasil studi kasus penentuan bibit kelapa sawit di PTPN IV Unit Kebun Bah Jambi. Adapun data yang didapat adalah data bibit kelapa sawit yang akan digunakan sebagai data kriteria penentuan bibit kelapa sawit serta aturan bobot untuk masing-masing kriteria untuk kebutuhan dan penelitian. 


\section{ANALISA DAN PEMBAHASAN}

\subsection{Proses Perhitungan Dengan Profile Matching}

Langkah awal dalam perhitungan profile matching ialah menentukan alternatif dan kriteria[4].

Tabel 1. Nama Alternatif

\begin{tabular}{clc}
\hline No & Nama Alternatif & Alternatif \\
\hline 1 & PPKS Socfindo & A1 \\
2 & PPKS Langkat & A2 \\
3 & PPKS Lonsum & A3 \\
4 & PPKS Bah Jambi & A4 \\
5 & PPKS Agro & A5 \\
6 & PPKS Avros & A6 \\
7 & PPKS Marihat & A7 \\
8 & PPKS Langkat & A8 \\
9 & PPKS Yangambi & A9 \\
10 & PPKS Sungai pancur & A10 \\
\hline
\end{tabular}

Langkah selanjutnya menentukan nilai bobot kriteria, sub kriteria serta type dari masing-masing sub kriteria yang digunakan dalam proses perhitungan dengan metode profile matching.

Tabel 2. Hasil Perhitungan Aspek Kriteria

\begin{tabular}{|c|c|c|c|c|c|}
\hline No & Nama Kriteria & Presentase & $\begin{array}{c}\text { Nilai Bobot } \\
\text { Sub Kriteria }\end{array}$ & Type & $\begin{array}{c}\text { Nilai } \\
\text { Persen }\end{array}$ \\
\hline 1 & $\begin{array}{l}\text { Daun } \\
\text { - Umur Daun } \\
\text {-Pola desun daun }\end{array}$ & $50 \%$ & $\begin{array}{l}5 \\
4\end{array}$ & $\begin{array}{l}\text { Core Factor } \\
\text { Secondary } \\
\text { Factor }\end{array}$ & $\begin{array}{l}60 \% \\
40 \%\end{array}$ \\
\hline 2 & $\begin{array}{l}\text { Batang } \\
\text {-Penebalan Batang } \\
\text {-Pengecilan Batang }\end{array}$ & $30 \%$ & $\begin{array}{l}4 \\
4\end{array}$ & $\begin{array}{l}\text { Core Factor } \\
\text { Secondary } \\
\text { Factor }\end{array}$ & $\begin{array}{l}60 \% \\
40 \%\end{array}$ \\
\hline 3 & $\begin{array}{l}\text { Tanah } \\
\text { - Latosol } \\
\text { - Organosol }\end{array}$ & $20 \%$ & $\begin{array}{l}3 \\
3\end{array}$ & $\begin{array}{l}\text { Core Factor } \\
\text { Secondary } \\
\text { Factor }\end{array}$ & $\begin{array}{l}60 \% \\
40 \%\end{array}$ \\
\hline
\end{tabular}

Nilai aspek merupakan acuan dalam mengubah data yang akan digunakan pada penelitian ini.

Tabel 3. Nilai Aspek

\begin{tabular}{lll}
\hline Nilai Kriteria & 1 & Tidak memenuhi syarat \\
& 2 & Kurang \\
& 3 & Cukup \\
& 4 & Baik \\
& 5 & Sangat Baik \\
\hline
\end{tabular}

Data yang digunakan sebagai objek penelitian didapat dari hasil studi kasus penentuan bibit kelapa sawit di PTPN IV Unit Kebun Bah Jambi. Adapun data yang didapat adalah data bibit kelapa sawit yang akan digunakan sebagai data kriteria penentuan bibit kelapa sawit serta aturan bobot untuk masing-masing kriteria sebagai penelitian.

Tabel 4. Penilaian

\begin{tabular}{cccccccc}
\hline \multirow{2}{*}{ No } & \multirow{2}{*}{ Nama Bibit Kelapa Sawit } & \multicolumn{2}{c}{ Daun } & \multicolumn{3}{c}{ Batang } & \multicolumn{2}{c}{ Tanah } \\
\cline { 3 - 7 } & & A1 & A2 & B1 & B2 & C1 & C2 \\
\hline 1 & Alternatif 1 & 5 & 4 & 4 & 5 & 3 & 5 \\
2 & Alternatif 2 & 5 & 3 & 4 & 5 & 3 & 4 \\
3 & Alternatif 3 & 4 & 4 & 5 & 4 & 5 & 2 \\
4 & Alternatif 4 & 5 & 5 & 4 & 4 & 4 & 3 \\
5 & Alternatif 5 & 5 & 2 & 5 & 3 & 4 & 4 \\
6 & Alternatif 6 & 4 & 3 & 5 & 5 & 5 & 4 \\
7 & Alternatif 7 & 4 & 4 & 3 & 4 & 3 & 5 \\
\hline
\end{tabular}




\begin{tabular}{cccccccc}
\hline \multirow{2}{*}{ No } & \multirow{2}{*}{ Nama Bibit Kelapa Sawit } & \multicolumn{2}{c}{ Daun } & \multicolumn{2}{c}{ Batang } & \multicolumn{2}{c}{ Tanah } \\
\cline { 3 - 8 } & & A1 & A2 & B1 & B2 & C1 & C2 \\
\hline 8 & Alternatif 8 & 5 & 4 & 4 & 2 & 2 & 5 \\
9 & Alternatif 9 & 5 & 4 & 3 & 4 & 2 & 3 \\
10 & Alternatif 10 & 5 & 3 & 3 & 5 & 3 & 4 \\
\hline
\end{tabular}
sawit.

Berikut adalah Tabel Aspek Daun algoritma Profile Matching dalam merekomendasikan bibit kelapa

Tabel 5. Aspek Daun

\begin{tabular}{cccc}
\hline \multirow{2}{*}{ No } & \multirow{2}{*}{ Nama Bibit Kelapa Sawit } & \multicolumn{2}{c}{ Daun } \\
\cline { 3 - 4 } & A1 & A2 \\
\hline 1 & Alternatif 1 & 5 & 4 \\
2 & Alternatif 2 & 5 & 3 \\
3 & Alternatif 3 & 4 & 4 \\
4 & Alternatif 4 & 5 & 5 \\
5 & Alternatif 5 & 5 & 2 \\
6 & Alternatif 6 & 4 & 3 \\
7 & Alternatif 7 & 4 & 4 \\
8 & Alternatif 8 & 5 & 4 \\
9 & Alternatif 9 & 5 & 4 \\
10 & Alternatif 10 & 5 & 3 \\
& Profil Pencapaian & 5 & 4 \\
1 & Alternatif 1 & 0 & 0 \\
2 & Alternatif 2 & 0 & -1 \\
3 & Alternatif 3 & -1 & 0 \\
4 & Alternatif 4 & 0 & 1 \\
5 & Alternatif 5 & 0 & -2 \\
6 & Alternatif 6 & -1 & -1 \\
7 & Alternatif 7 & -1 & 0 \\
8 & Alternatif 8 & 0 & 0 \\
9 & Alternatif 9 & 0 & 0 \\
10 & Alternatif 10 & 0 & -1 \\
\hline
\end{tabular}

Nilai bobot yang merupakan nilai konstanta dapat dilihat pada tabel 5 sebagai berikut.

Tabel 6. Nilai Bobot

\begin{tabular}{cccc}
\hline No & Selisih & Nilai Bobot & Keterangan \\
\hline 1 & 0 & 5 & Tidak Ada Selisih \\
2 & 1 & 4.5 & Kompeten Individu Kelebihan 1 Tingkat Level \\
3 & -1 & 4 & Kompeten Individu Kekurangan 1 Tingkat Level \\
4 & 2 & 3.5 & Kompeten Individu Kelebihan 2 Tingkat Level \\
5 & -2 & 3 & Kompeten Individu Kekurangan 2 Tingkat Level \\
6 & 3 & 2.5 & Kompeten Individu Kelebihan 3 Tingkat Level \\
7 & -3 & 2 & Kompeten Individu Kekurangan 3 Tingkat Level \\
8 & 4 & 1.5 & Kompeten Individu Kelebihan 4 Tingkat Level \\
9 & -4 & 1 & Kompeten Individu Kekurangan 4 Tingkat Level
\end{tabular}
merekomendasikan bibit kelapa sawit;

\begin{tabular}{clcc}
\multicolumn{2}{c}{ Tabel 7. Nilai Bobot Aspek Daun } \\
\hline \multirow{2}{*}{ No } & \multirow{2}{*}{ Nama Bibit Sawit } & \multicolumn{2}{c}{ Daun } \\
\cline { 3 - 4 } & & A1 & A2 \\
\hline 1 & Alternatif 1 & 0 & 0 \\
2 & Alternatif 2 & 0 & -1 \\
3 & Alternatif 3 & -1 & 0 \\
4 & Alternatif 4 & 0 & 1 \\
5 & Alternatif 5 & 0 & -2 \\
6 & Alternatif 6 & -1 & -1 \\
7 & Alternatif 7 & -1 & 0 \\
8 & Alternatif 8 & 0 & 0 \\
9 & Alternatif 9 & 0 & 0
\end{tabular}




\begin{tabular}{clcc}
10 & Alternatif 10 & 0 & -1 \\
& Nilai Bobot & & \\
1 & Alternatif 1 & 5 & 5 \\
2 & Alternatif 2 & 5 & 4 \\
3 & Alternatif 3 & 4 & 5 \\
4 & Alternatif 4 & 5 & 4.5 \\
5 & Alternatif 5 & 5 & 3 \\
6 & Alternatif 6 & 4 & 4 \\
7 & Alternatif 7 & 4 & 5 \\
8 & Alternatif 8 & 5 & 5 \\
9 & Alternatif 9 & 5 & 5 \\
10 & Alternatif 10 & 5 & 4 \\
\hline
\end{tabular}

Perhitungan Aspek Daun

Berdasarkan nilai bobot pada tabel diatas, maka dapat dihitung menggunakan persamaaan 1 .

$$
\begin{aligned}
\mathrm{A} 1 & =\frac{5}{1}=5(\mathrm{NCF}) \\
& =\frac{5}{1}=5(\mathrm{NSF}) \\
\mathrm{A} 2 & =\frac{5}{1}=5(\mathrm{NCF}) \\
& =\frac{4}{1}=4(\mathrm{NSF}) \\
\mathrm{A} 3 & =\frac{4}{1}=4(\mathrm{NCF}) \\
& =\frac{5}{1}=5(\mathrm{NSF})
\end{aligned}
$$

\begin{tabular}{|c|c|c|c|c|c|}
\hline \multirow{2}{*}{ No } & \multirow{2}{*}{ Nama Bibit Sawit } & \multicolumn{2}{|c|}{ Daun } & \multirow{2}{*}{ NCF } & \multirow{2}{*}{ NSF } \\
\hline & & A1 & A2 & & \\
\hline 1 & Alternatif 1 & 5 & 5 & 5 & 5 \\
\hline 2 & Alternatif 2 & 5 & 4 & 5 & 4 \\
\hline 3 & Alternatif 3 & 4 & 5 & 4 & 5 \\
\hline 4 & Alternatif 4 & 5 & 4.5 & 5 & 4.5 \\
\hline 5 & Alternatif 5 & 5 & 3 & 5 & 3 \\
\hline 6 & Alternatif 6 & 4 & 4 & 4 & 4 \\
\hline 7 & Alternatif 7 & 4 & 5 & 4 & 5 \\
\hline 8 & Alternatif 8 & 5 & 5 & 5 & 5 \\
\hline 9 & Alternatif 9 & 5 & 5 & 5 & 5 \\
\hline 10 & Alternatif 10 & 5 & 4 & 5 & 4 \\
\hline
\end{tabular}

Berikut adalah Tabel Bobot Nilai Gap Aspek Daun algoritma Profile Matching dalam merekomendasikan bibit kelapa sawit;

Tabel 8. Bobot Nilai Gap Aspek Daun

Perhitungan Nilai Total

Perhitungan Nilai Total menggunakan persamaan 2 sehingga diperoleh:

$$
\begin{aligned}
\mathrm{A} 1 & =(60 \% * 5)+(40 \% * 5) \\
& =3+2 \\
& =5 \\
\mathrm{~A} 2 & =(60 \% * 5)+(40 \% * 4) \\
& =4,6 \\
\mathrm{~A} 3 & =(60 \% * 4)+(40 \% * 5) \\
& =2,4+2 \\
& =4,4 \\
\mathrm{~A} 4 & =(60 \% * 5)+(40 \% * 4,5) \\
& =3+1,8 \\
& =4,8
\end{aligned}
$$

Penentuan Hasil Akhir Penelitian

Berikut adalah Perhitungan Penentuan Hasil Akhir Penelitian menggunakan persamaan 3 sehingga diperoleh :

$$
\begin{aligned}
\mathrm{A} 1 & =(50 \% * 5)+(30 \% * 4,8)+(20 \% * 4,4) \\
& =2,5+1,44+0,88 \\
& =4.82 \\
\mathrm{~A} 2 & =(50 \% * 4,6)+(30 \% * 4,8)+(20 \% * 4,8)
\end{aligned}
$$




$$
\begin{aligned}
& =2,3+1,44+0,96 \\
& =4.7 \\
\text { A } 3 & =(50 \% * 4,4)+(30 \% * 4,7)+(20 \% * 3,7) \\
& =2,2+1,41+0,74 \\
& =4.35 \\
\text { A4 } & =(50 \% * 4,8)+(30 \% * 5)+(20 \% * 4,7) \\
& =2,4+1,5+0,94 \\
& =4.84
\end{aligned}
$$

Berikut adalah Tabel Hasil Akhir Penelitian algoritma Profile Matching dalam merekomendasikan bibit kelapa sawit.

Tabel. 10. Hasil Akhir Penelitian

\begin{tabular}{clccccr}
\hline No & Nama Bibit Sawit & N (a) & N (b) & N ( c ) & Hasil akhir & Rangking \\
\hline 1 & Alternatif 1 & 5 & 4.9 & 4.55 & 4.82 & 2 \\
2 & Alternatif 2 & 4.6 & 4.9 & 4.85 & 4.7 & 4 \\
3 & Alternatif 3 & 4.4 & 4.6 & 3.65 & 4.35 & 8 \\
4 & Alternatif 4 & 4.8 & 5 & 4.65 & 4.84 & 1 \\
5 & Alternatif 5 & 4.2 & 4.4 & 4.5 & 4.29 & 9 \\
6 & Alternatif 6 & 4 & 4.5 & 3.8 & 4.13 & 10 \\
7 & Alternatif 7 & 4.4 & 4.2 & 4.55 & 4.4 & 7 \\
8 & Alternatif 8 & 5 & 4.6 & 3.85 & 4.52 & 5 \\
9 & Alternatif 9 & 5 & 4.2 & 4.3 & 4.7 & 3 \\
10 & Alternatif 10 & 4.6 & 4.1 & 4.85 & 4.52 & 6 \\
\hline
\end{tabular}

Form ini Digunakan untuk menyimpan data Hasil Akhir. Tampilan data Hasil Akhir dapat dilihat pada gambar 1.

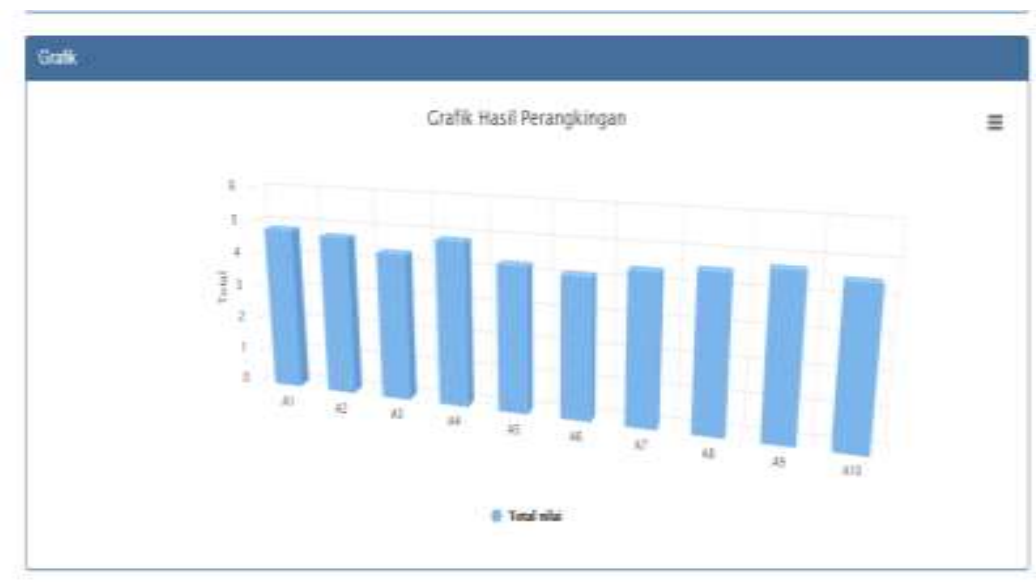

\section{Gambar 1. Tampilan Form Hasil Akhir}

Dari tampilan grafik perangkingan untuk hasil akhir diatas menjelaskan A1 total nilai sebesar 4.820, A2 total nilai sebesar 4.700, A3 total nilai sebesar 4.350, A4 total nilai sebesar 4.840, A5 total nilai sebesar 4.290, A6 total nilai sebesar 4.130, A7 total nilai sebesar 4.400,A8 total nilai sebesar 4.520, A9 total nilai sebesar 4.700, A10 total nilai sebesar 4520 .

\section{KESIMPULAN}

Sistem pendukung keputusan dalam merekomendasikan bibit kelapa sawit dengan menggunakan algoritma profile matching memiliki beberapa kesimpulan, yaitu :

1. Dengan adanya sistem ini kantor Unit Usaha Kebun Bah Jambi dapat terbantu dalam mengolah data prangkingan.

2. Dalam menentukan bibit kelapa sawit di kantor Unit Usaha Kebun Bah Jambi dapat diselesaikan dengan metode Profile Matching.

3. Sistem memberikan solusi rekomendasi kepada pengguna sesuai dengan kriteria dan bobot yang ditentukan.

4. Sistem yang dibangun hanyalah sebagai alat bantu untuk memberikan informasi kepada pimpinan sebagai bahan pertimbangan dalam mengambil keputusan. 


\section{REFERENCES}

[1] E. Satria, N. Atina, M. E. Simbolon, And A. P. Windarto, Spk: Algoritma Multi-Attribute Utility Theory ( Maut ) Padadestinasi Tujuan Wisata Lokal Di Kota Sidamanik, Cess(Journal Comput. Eng. Syst. Sci., Vol. 3, No. 2, Pp. 168-172, 2018.

[2] S. Sundari Et Al., Sistem Pendukung Keputusan Dengan Menggunakan Metode Electre Dalam Merekomendasikan Dosen Berprestasi Bidang Ilmu Komputer ( Study Kasus Di Amik \& Stikom Tunas Bangsa ), In Prosiding Seminar Nasional MultiDisiplin Ilmu (Senasmudi), 2017, Pp. 1-6.

[3] A. Setiawan, Sutardi, Tajidun, Lm, 2017, And J. T. Informatika, Spk Penilaian Dan Pemberian Bonus Salesman Pada Matakar Kendari Menggunakan Profile Matching, Semantik, Vol. 3, No. 1, Pp. 199-208, 2017.

[4] R. Hidayat, Menentukan Promosi Jabatan Karyawan Dengan Menggunakan Metode Profile Matching Dan Metode Promethee, Ijse, Vol. 2, No. 1, Pp. 57-65, 2016. 